\title{
Factors associated with post-traumatic stress disorder and depression amongst internally displaced persons in northern Uganda
}

\author{
Bayard Roberts*1, Kaducu Felix Ocaka², John Browne ${ }^{3}$, Thomas Oyok ${ }^{2}$ and \\ Egbert Sondorp ${ }^{1}$
}

Address: ${ }^{1}$ Conflict and Health Programme, Health Policy Unit, Department of Public Health and Policy, London School of Hygiene and Tropical Medicine, Keppel Street, London, WC1E 7HT, UK, ${ }^{2}$ Faculty of Medicine, Gulu University, PO Box 166, Gulu, Uganda and ${ }^{3}$ Health Services Research Unit, Department of Public Health and Policy, London School of Hygiene and Tropical Medicine, Keppel Street, London, WC1E 7HT, UK

Email: Bayard Roberts* - bayard.roberts@lshtm.ac.uk; Kaducu Felix Ocaka - fkaducu@yahoo.co.uk; John Browne - john.browne@lshtm.ac.uk; Thomas Oyok - oyokthomas@yahoo.co.uk; Egbert Sondorp - egbert.sondorp@lshtm.ac.uk

* Corresponding author

Published: 19 May 2008

BMC Psychiatry 2008, 8:38 doi:10.1 186/147|-244X-8-38
Received: 12 February 2008

Accepted: 19 May 2008

This article is available from: http://www.biomedcentral.com/I47I-244X/8/38

(c) 2008 Roberts et al; licensee BioMed Central Ltd.

This is an Open Access article distributed under the terms of the Creative Commons Attribution License (http://creativecommons.org/licenses/by/2.0), which permits unrestricted use, distribution, and reproduction in any medium, provided the original work is properly cited.

\begin{abstract}
Background: The 20 year war in northern Uganda between the Lord's Resistance Army and the Ugandan government has resulted in the displacement of up to 2 million people within Uganda. The purpose of the study was to measure rates of post-traumatic stress disorder (PTSD) and depression amongst these internally displaced persons (IDPs), and investigate associated demographic and trauma exposure risk factors.
\end{abstract}

Methods: A cross-sectional multi-staged, random cluster survey with 1210 adult IDPs was conducted in November 2006 in Gulu and Amuru districts of northern Uganda. Levels of exposure to traumatic events and PTSD were measured using the Harvard Trauma Questionnaire (original version), and levels of depression were measured using the Hopkins Symptom Checklist-25. Multivariate logistic regression was used to analyse the association of demographic and trauma exposure variables on the outcomes of PTSD and depression.

Results: Over half (54\%) of the respondents met symptom criteria for PTSD, and over two thirds (67\%) of respondents met symptom criteria for depression. Over half (58\%) of respondents had experienced 8 or more of the 16 trauma events covered in the questionnaire. Factors strongly linked with PTSD and depression included gender, marital status, distance of displacement, experiencing ill health without medical care, experiencing rape or sexual abuse, experiencing lack of food or water, and experiencing higher rates of trauma exposure.

Conclusion: This study provides evidence of exposure to traumatic events and deprivation of essential goods and services suffered by IDPs, and the resultant effect this has upon their mental health. Protection and social and psychological assistance are urgently required to help IDPs in northern Uganda re-build their lives. 


\section{Background}

There have been up to 2 million internally displaced persons (IDPs) in northern Uganda as a result of the 20 year conflict waged largely between a rebel group, the Lord's Resistance Army, and the central government and its army. Negotiations between the LRA and the Ugandan government have taken place since July 2006 but a peace settlement is yet to be signed [1]. The IDPs are based predominantly in the most conflict-affected districts of Gulu, Amuru, Kitgum and Pader which are mainly populated by the Acholi people. Up to $80 \%$ of the population in these districts are IDPs, and an estimated $85 \%$ of these IDPs live in government organised camps. The IDPs were forced to move to the camps by the Ugandan army to reportedly protect the civilians and aid the army's counter-insurgency campaign against the Lords Resistance Army [2]. The camps are characterised by chronic over-crowding, insecurity, social problems, and high rates of morbidity and mortality [3-5]. The civilian population has suffered indiscriminate killings, assaults, and the abduction of children to become fighters, forced labourers, and sex slaves [6-8]. The purpose of the study was to measure rates of posttraumatic stress disorder (PTSD) and depression amongst internally displaced persons (IDPs), and investigate associated demographic and trauma exposure risk factors.

\section{Methods}

The study took place in November 2006 in Gulu and Amuru districts of northern Uganda (Amuru district was separated out from Gulu district in July 2006). The two districts contain an estimated 650,000 IDPs which is approximately $40 \%$ of all IDPs in Uganda. Up to $80 \%$ of the districts' population live in camps which range in size from 1,100 to almost $60,000[9,10]$. A cross-sectional survey design was used. The sampling population included adult ( $\geq 18$ years old) male and female IDPs. IDPs were defined as people living in the officially recognised IDP camps in Gulu and Amuru districts. The study used the SF8 as an outcome measure (with the findings presented elsewhere) and the sample size was calculated to detect associations of independent variables on this continuous outcome variable. The sample size required adequate power $(80 \%)$ to detect conceptually important differences ( 0.8 standard deviation) in the health outcomes of different respondent groups within a multivariate analysis with a significance level of $5 \%$ with the size of the 'rarest' subgroup of respondents at 5\% [11]. Due to the cluster sampling method used, a design effect of 2.0 was included which doubled the required sample size [12]. The expected proportion of unusable questionnaires was set at $10 \%$. The resultant sample size required was calculated to be a minimum of 1080 .

An adapted multi-stage cluster sampling method was used as random and systematic sampling methods were not feasible in the IDP camps due limited data on the population and the unsystematic layouts of the camps [12]. The first stage was to randomly select the camps from which the clusters would be chosen. The sampling frame was a list of the total population of IDPs living in all the 65 officially recognised IDP camps in Gulu and Amuru districts [10]. The data for this list was collected by the World Food Programme in August 2006 and considered to be the most accurate IDP population data available in the two districts. 32 clusters were chosen rather than the more common use of 30 clusters to reduce the design effect [13]. The 32 clusters were selected using the probability proportional to size technique. This used the World Food Programme list of the 65 officially recognised IDP camps in Gulu and Amuru districts, with a corresponding running cumulative population size for each camp. Clusters were then allocated to camps proportionally to the camp population sizes following the probability proportional to size technique to ensure self-weighting [12]. The 32 clusters were allocated to 28 IDP camps using this process. The total population living in the 28 selected camps was 452,702 .

Due to the large population sizes of the selected camps, a second stage was used to randomly select administrative zones within the sampled IDP camps as second stage units to act as individual clusters. These were existing zones established by the camp authorities and were estimated to be of similar population sizes based upon discussions with camp and zone leaders, and so self-weighting was maintained. The third stage consisted of randomly choosing individuals from the selected clusters. As the clusters were already self-weighted, the same number of individuals were chosen from within each of the selected clusters. The Expanded Programme on Immunisation (EPI) method was used to randomly select households for this stage and one individual was then randomly selected from the eligible individuals within the household [13$15]$.

Two study staff conducted stage 2 and 3 of the sampling process through a pre-visit the day before the actual data collection. In stage 3, if the randomly selected person was not present, another adult member of the household or a neighbour were asked to inform the selected person to attend the data collection visit. The random selection process was emphasised to avoid accusations of favouritism or risk of stigmatisation against the selected person. It was advised that replacements would not be accepted and precautions were taken to reduce risk of replacements. If a household had been deserted for more than 1 month, EPI methods were followed to select another household.

A questionnaire was developed consisting of items on the demographic and socio-economic characteristics of the 
respondents, and existing health measurement instruments to measure trauma exposure, PTSD and depression. A slightly adapted version of the original Harvard Trauma Questionnaire (HTQ) was used to identify exposure to trauma events [16]. This consisted of 16 questions on lifetime exposure to traumatic events with a 'yes/no' response. PTSD was measured using 30 questions on trauma symptoms with a 4 point severity scale and a recall period of 1 week. The first 16 items are based upon the Diagnostic and Statistical Manual for Mental Disorders, Fourth Edition (DSM-IV), and the remaining 14 items developed specifically for conflict-affected persons $[16,17]$. Mean PTSD scores $\geq 2.0$ were considered significant for meeting symptom criteria of probable PTSD based upon the instrument standards [18]. Scores for symptoms of probable depression were measured using the 15 depression items from the Hopkins Symptoms Check List-25 (HSCL-25) [18,19]. This also has a 4 point severity scale and a recall period of 1 week. Mean depression scores $\geq 1.75$ were considered significant for meeting symptom criteria of probable depression based upon the instrument standards [18]. The 15 depression items are consistent with the depression items in the DSM-IV $[17,19]$. The reliability and validity of the HTQ and HSCL25 have been tested and proven for use with displaced persons in a number of countries [16,19-24]. The questionnaire was translated and delivered in Luo, the main language of Gulu and Amuru districts. The translation followed recommended guidelines, and involved forward and back translation, and detailed review by the study team $[16,18]$.

A team of 15 data collectors were recruited for the survey ( 8 men and 7 women) who were all from the Acholi region of northern Uganda, spoke fluent Luo and English, and had experience of data collection in IDP camps in northern Uganda. Six days training was provided for the study. The data collection took place between 6 and 27 November 2006. Each interview took between 35 and 45 minutes approximately. A consent form was used to ensure informed consent and clarify that no direct benefit could be expected from participating in the study. All data collected was confidential and anonymous. Ethical approval for the study was provided by the Ugandan National Council for Science and Technology, Gulu University, and the London School of Hygiene and Tropical Medicine. As some of the questions were on traumatic experiences and mental distress, referral information for support on mental health was provided. One of the study team was a psychiatrist and one of the team leaders was a double trained Clinical Psychiatric Officer/Mental Health Nurse who could offer advice if required. Supervision and quality control were provided by the 3 members of the study team and 2 team leaders.
Two data entry clerks were used to enter the data into SPSS, version 14.0 (SPSS Inc, Chicago, USA). Each questionnaire was cross-checked by project staff and analysis conducted of the dataset to check for inconsistent data entries. Analysis was performed using STATA version 9.2 (Stata Corporation, College Park, Texas, USA) and adjusted for the clustered design. The Cronback $\alpha$ for internal consistency reliability was tested and estimated at 0.86 for the PTSD scale and 0.83 for the depression scale, above the generally accepted minimum threshold level of $\geq 0.70$ for an internal reliability coefficient [25]. Multivariate logistic regression was applied to produce odds ratios (OR) of associations between independent demographic and trauma exposure variables with outcomes of PTSD and depression and adjusted to address the influence of the other significant variables. Based upon the cut off levels given in the instrument guidelines, the outcome of PTSD was dichotomised into respondents exhibiting or not exhibiting signs of PTSD (cut off $\geq 2.0$ ), and the outcome of depression dichotomised into respondents exhibiting not exhibiting signs of depression (cut off $\geq 1.75$ ) [18]. Continuous independent variables were also categorised for the analysis. All trauma exposure variables were included in the multivariate analyses. All demographic variables which were statistically significant $(P<$ 0.05 ) following a univariate analysis to test for strength of association were included for the multivariate analysis. The associations in the multivariate analysis which were statistically significant $(P<0.05)$ using a backward elimination regression approach were included in the final results. Separate regression models were used for the association of independent trauma events and the cumulative events on the outcomes of PTSD and depression. Statistical interaction between independent variables was tested but none were significant $(P<0.05)$.

\section{Results}

A total of 32 clusters were surveyed in 28 camps in Gulu and Amuru districts as planned. Table 1 presents the sampling profile of the survey. The overall response rate was $94.5 \%$.

Table I: Sampling profile

\begin{tabular}{lccc}
\hline & $\begin{array}{c}\text { Gulu } \\
\text { District }\end{array}$ & Amuru district & Total \\
\hline Camps visited & 17 & 11 & 28 \\
Absent individuals & 25 & 19 & 44 \\
Non-consenting individuals & 15 & 7 & 22 \\
$\begin{array}{l}\text { Incomplete individual } \\
\text { interviews }\end{array}$ & 1 & 3 & 4 \\
$\begin{array}{l}\text { Total individual replacement } \\
\text { Completed individual }\end{array}$ & 0 & 0 & 0 \\
interview & 641 & 569 & 1210 \\
\hline
\end{tabular}




\section{Sample characteristics}

The sample characteristics are provided in Table 2. A greater proportion of women $(60 \%)$ than men were in the sample. The mean age of respondents was 35.4 years and the main ethnic group was Acholi (91\%). Over two thirds $(68 \%)$ of respondents had been displaced for more than 5 years, and $41 \%$ had been displaced to 2 or more camps.

Table 2: Sample characteristics of Ugandan IDP respondents ( $N$ $=(210)$

\begin{tabular}{|c|c|}
\hline Characteristics & Number (\%) \\
\hline Number of women & $727(60.1)$ \\
\hline Age, mean & 35.3 years \\
\hline \multicolumn{2}{|l|}{ Religion } \\
\hline Catholic & $927(76.6)$ \\
\hline Protestant & $167(13.8)$ \\
\hline Born again Christian & $101(8.4)$ \\
\hline other & $15(1.2)$ \\
\hline \multicolumn{2}{|l|}{ Ethnicity } \\
\hline Acholi & $\mathrm{I}, 098(90.7)$ \\
\hline Lango & $88(7.3)$ \\
\hline Other & $24(2.0)$ \\
\hline \multicolumn{2}{|l|}{ Marital status } \\
\hline married/co-habiting & $926(76.5)$ \\
\hline single & $72(6.0)$ \\
\hline separated* & $212(17.5)$ \\
\hline \multicolumn{2}{|l|}{ Education level } \\
\hline never attended school & $380(31.4)$ \\
\hline completed primary school & $711(58.8)$ \\
\hline completed secondary school & $119(9.8)$ \\
\hline \multicolumn{2}{|c|}{ Personal income of previous month $\S$} \\
\hline$<25,000$ UGS & $732(60.5)$ \\
\hline $25,000-50,000$ UGS & $230(19.0)$ \\
\hline$>50,000$ UGS & $238(19.7)$ \\
\hline refused to answer & $10(0.8)$ \\
\hline \multicolumn{2}{|l|}{ Period since left village } \\
\hline Less than 12 months & $20(1.7)$ \\
\hline $1-2$ years & $69(5.7)$ \\
\hline $3-5$ years & $277(22.9)$ \\
\hline $5-10$ years & 479 (39.6) \\
\hline More than 10 years & $345(28.5)$ \\
\hline Don't Know & $20(1.7)$ \\
\hline \multicolumn{2}{|l|}{ Number of camps lived in } \\
\hline I camp & $7 I I(58.8)$ \\
\hline 2 camps & $386(31.90)$ \\
\hline 3 or more camps & $113(9.3)$ \\
\hline
\end{tabular}

Abbreviations: UGS, Ugandan shillings $\S I$ USD $=1800$ UGS at time of survey

* Separated: divorced/separated, widowed, forcibly separated

\section{Exposure to trauma}

The results on exposure to traumatic events are given in Table 3. Three quarters $(75 \%)$ of respondents had witnessed or experienced the murder of a family or friend. Nearly two thirds $(64 \%)$ of respondents had witnessed the murder of a stranger or strangers. More than half (56\%) reported having been beaten or tortured. More than $40 \%$ reported having been kidnapped and $14 \%$ reported having been raped or sexually abused. Over half (58\%) of respondents had experienced 8 or more of the 16 trauma events covered in the questionnaire. The distribution of the exposure to traumatic events is shown in Figure 1.

There were significant variations between women and men in exposure to a number of the traumatic events. $47 \%$ [95\% CI 41.99-51.61] of women and 70\% [95\% CI 65.01-74.89] of men had experienced being beaten or tortured. $18 \%$ [95\% CI 15.35-21.97] of women and 8\% [95\% CI 5.37-10.82] of men had been raped or sexually abused. 31\% [95\% CI 26.8-35.14] of women and $62 \%$ [95\% CI 56.34-67.56] of men had been abducted. $13 \%$ [95\% CI 11.00-16.10] of women and 41\% [95\% CI 36.646.39] of men had been imprisoned. 23\% [95\% CI 19.26-26.54] of women and 34\% [95\% CI 28.79-39.97] of men had been involved in combat. 49\% [95\% CI $44.47-52.93$ ] of women and 71\% [95\% CI 67.19-75.32] of men had experienced 8 or more traumatic events.

Deprivation by IDPs of material and social goods is evidenced by the fact that $90 \%$ respondents had experienced lack of food or water, over two thirds $(65 \%)$ had been ill without medical care, and over three quarters $(77 \%)$ had lacked housing or shelter. Over half of the traumatic events listed in Table 3 had occurred whilst the participants were living in a camp. 93\% did not feel safe in the camp in which they lived. The main reasons cited for this perceived lack of safety were lack of food $(62 \%)$, fear of disease outbreak (61\%), and insecurity and fear of armed forces $(54 \%)$.

\section{Prevalence of PTSD and depression}

More than half (54\%) of respondents met symptom criteria for PTSD (Table 4). 60\% of women met symptom criteria for PTSD. Over two thirds (67\%) of respondents met symptom criteria for depression. $78 \%$ of women met symptom criteria for PTSD. The distribution of the scores for PTSD and depression are shown in Figures 2 and 3.

\section{Multivariate analysis}

Table 5 shows the statistically significant $(P<0.05)$ adjusted odds ratio results of the multivariate logistic regression analysis on the association of key demographic and trauma exposure variables on the outcomes of PTSD (cut off $\geq 2.0$ ) and depression (cut off $\geq 1.75$ ). These show 
Table 3: Exposure to Traumatic Events $(N=|2| 0)$

\begin{tabular}{|c|c|c|c|c|}
\hline \multirow[t]{2}{*}{ Variables } & \multicolumn{3}{|c|}{ Number of persons experiencing event } & \multirow[t]{2}{*}{ Total (\%) $[95 \% \mathrm{Cl}]$} \\
\hline & Before living in camp & When living in camp & before and when living in camp & \\
\hline \multicolumn{5}{|l|}{ Trauma event experienced } \\
\hline lack of food or water & 77 & 940 & 71 & $1088(89.9)$ [87.9-91.7] \\
\hline lack of housing or shelter & 76 & 815 & 44 & 935 (77.3) [73.5-80.7] \\
\hline unnatural death of family/friend & 524 & 298 & 93 & 915 (75.6) [73.7-77.5] \\
\hline murder of family member/friend & 578 & 236 & 91 & 905 (74.8) [7I.4-78.0] \\
\hline being close to, but escaping, death & 549 & 249 & 47 & $845(69.8)[67.0-72.6]$ \\
\hline ill health without medical care & 176 & 554 & 57 & $787(65.0)[61.8-68.2]$ \\
\hline witnessing murder of stranger(s) & 390 & 308 & 80 & $778(64.3)[6 \mid .4-67.1]$ \\
\hline tortured or beaten & 469 & $|8|$ & 29 & $679(56.1)[52.4-59.8]$ \\
\hline forced separation from family & 392 & 133 & 25 & $550(45.5)[42.6-48.3]$ \\
\hline being abducted or kidnapped & 370 & 133 & 21 & $524(43.3)[39.8-46.9]$ \\
\hline made to accept ideas against will & 147 & 279 & 57 & $483(39.9)[36.6-43.5]$ \\
\hline serious injury & 282 & 178 & 14 & $474(39.2)[36.1-42.4]$ \\
\hline forced isolation from other people & 293 & 149 & 10 & $452(37.4)[34.3-40.6]$ \\
\hline being in a war fighting situation & 235 & 85 & 10 & $330(27.3)[24.0-30.9]$ \\
\hline imprisonment against your will & 187 & 101 & 9 & $297(24.5)[22.0-27.3]$ \\
\hline rape or sexual abuse & 78 & 83 & 10 & $17 \mid(14.1)[11.8-16.8]$ \\
\hline \multicolumn{5}{|l|}{ Cumulative trauma events recorded } \\
\hline $0-3$ trauma events & & & & $103(8.5)[7.2-10.0]$ \\
\hline 4-7 trauma events & & & & $408(33.7)[30.8-36.8]$ \\
\hline $8-11$ trauma events & & & & $425(35.1)[32.7-37.6]$ \\
\hline $12-16$ trauma events & & & & $274(22.6)[20.0-25.6]$ \\
\hline
\end{tabular}

Abbreviations: $\mathrm{Cl}$, confidence interval.

a strong association of gender on mental distress, with women twice as likely as men to be exhibit symptoms of PTSD (OR 2.06 [95\% CI 1.49-2.84]) and over 4 times as likely as men to exhibit symptoms of depression (OR 4.32 [95\% CI 2.80-6.66]). Other demographic variables associated with mental distress include the marital status of respondents, with respondents who were no longer married (divorced/separated, widowed, or forced separation)

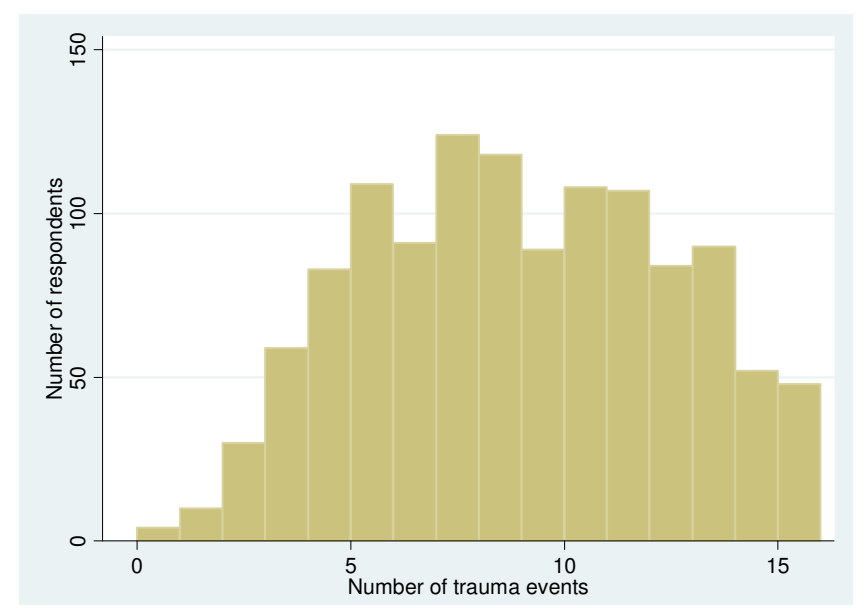

Figure I

Distribution of trauma exposure $(\mathrm{N}=1210)$. more likely than married respondents to exhibit symptoms of PTSD (OR 1.80 [95\% CI 1.25-2.59]) and depression (OR 2.41 [95\% CI 1.36-4.27]). The distance of displacement (camp $>5$ miles from home village) was also associated with depression (OR 1.47 [95\% CI 1.16$1.85])$.

The individual trauma exposures with the strongest associations with PTSD were ill health without medical care

Table 4: Prevalence rate of PTSD and depression

\begin{tabular}{lc}
\hline Variable & Total (\%) [95\% Cl] \\
\hline Symptoms of PTSD & \\
men $(n=483)$ & $220(45.6)[39.9-51.3]$ \\
women $(n=727)$ & $437(60.1)[55.8-64.2]$ \\
total $(n=1210)$ & $657(54.3)[50.4-58.1]$ \\
\hline Symptoms of depression & \\
men $(n=483)$ & $248(51.4)[45.8-56.9]$ \\
women $(n=727)$ & $567(78.0)[74.1-81.4]$ \\
total $(n=1210)$ & $815(67.4)[63.5-71.0]$
\end{tabular}

Abbreviations: $\mathrm{Cl}$, confidence interval; PTSD, post-traumatic stress disorder.

Symptoms of PTSD (HTQ PTSD Score $=\geq 2.0)$ and depression $(\mathrm{HSCL}$ score $=\geq 1.75)$

All results $P<0.05$ 


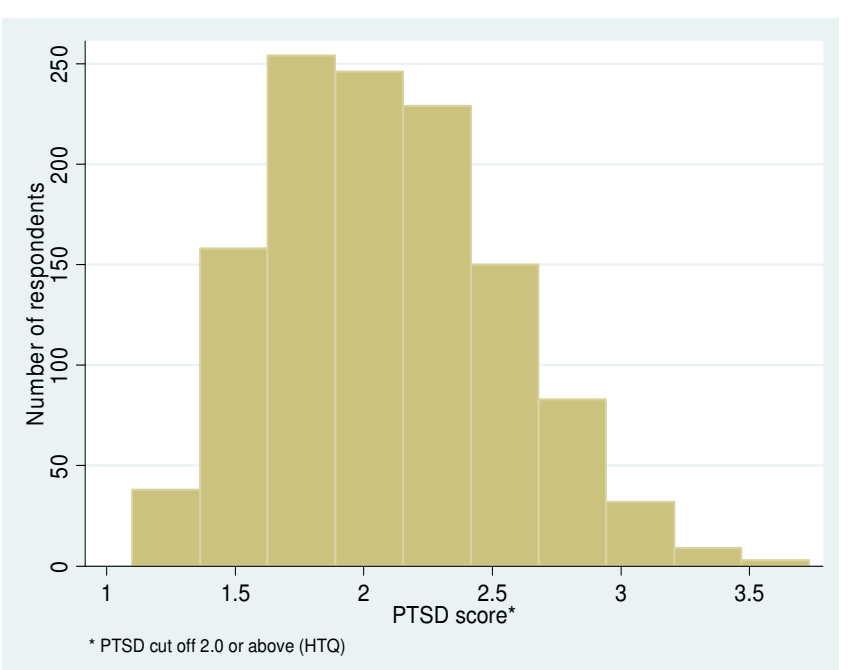

Figure 2

Distribution of PTSD scores $(\mathrm{N}=1210)$.

(OR 1.95 [95\% CI 1.52-2.51]); rape or sexual abuse (OR 1.67 [95\% CI 1.01-2.75]); and lack of food or water (OR 1.55 [95\% CI 1.00-2.39]). The individual trauma exposures with the strongest associations with depression were ill health without medical care (OR 1.97 [95\% CI 1.502.58]); lack of food or water (OR 1.64 [95\% CI 1.052.58]; and unnatural death of family/friend (OR 1.54 [95\% CI 1.10-2.16]).

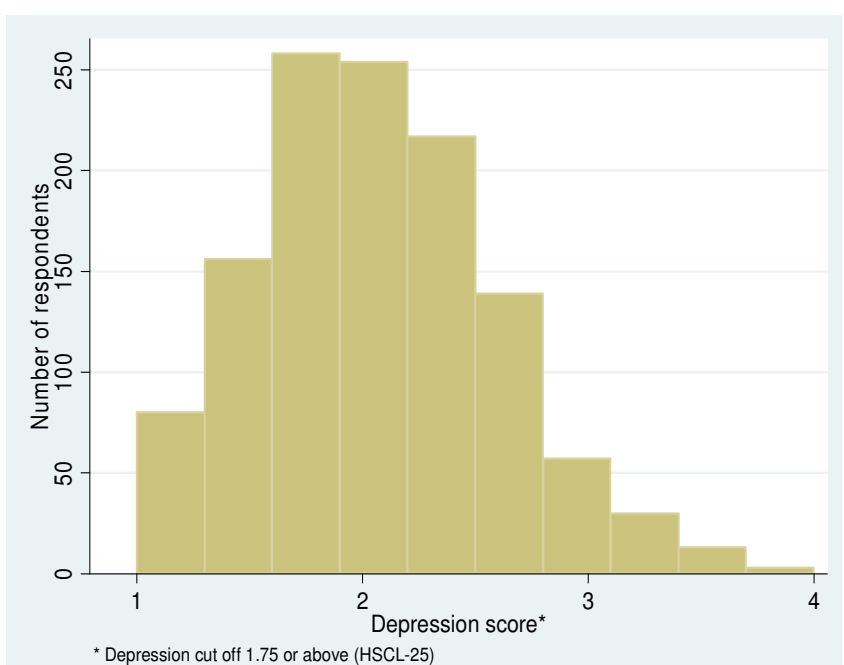

Figure 3

Distribution of depression scores $(N=1210)$.

Table 6 shows the statistically significant $(P<0.05)$ adjusted odds ratio results of the multivariate logistic regression analysis on the association of cumulative trauma exposure on the outcomes of PTSD (cut off $\geq 2.0$ ) and depression (cut off $\geq 1.75$ ). A higher frequency of exposure to traumatic events (experienced 12 or more of the 16 trauma events included in the questionnaire) was associated with exhibiting symptoms of PTSD (OR 6.5 [95\% CI 3.7-11.3]) and depression (OR 5.8 [95\% CI 3.59.7]).

Table 5: Multivariate analysis of demographic and individual trauma exposure variables associated with PTSD and depression

\begin{tabular}{|c|c|c|c|c|}
\hline \multirow[t]{2}{*}{ Variable } & \multicolumn{2}{|c|}{ PTSD (N = 657) } & \multicolumn{2}{|c|}{ Depression $(\mathbf{N}=815)$} \\
\hline & OR $[95 \% \mathrm{Cl}]$ & $P$ value & OR $[95 \% \mathrm{Cl}]$ & $P$ value \\
\hline \multicolumn{5}{|l|}{ Demographic Variables } \\
\hline Female & $2.06[1.49-2.84]$ & $<0.01$ & $4.32[2.80-6.66]$ & $<0.01$ \\
\hline no longer married* & $1.80[1.25-2.59]$ & $<0.01$ & $2.4 \mid[1.36-4.27]$ & $<0.01$ \\
\hline displaced $>5$ miles from home & NA & NA & $1.47[1.16-1.85]$ & $<0.01$ \\
\hline \multicolumn{5}{|l|}{ Trauma exposure variable } \\
\hline ill health without medical care & $1.95[1.52-2.51]$ & $<0.01$ & $1.97[1.50-2.58]$ & $<0.01$ \\
\hline rape or sexual abuse & $1.67[1.01-2.75]$ & 0.045 & $\mathrm{NA}$ & NA \\
\hline lack of food or water & $1.55[1.00-2.39]$ & 0.048 & $1.64[1.05-2.58]$ & 0.03 \\
\hline unnatural death of family/friend & NA & NA & $1.54[1.10-2.16]$ & 0.01 \\
\hline being tortured or beaten & $1.42[1.09-1.84]$ & 0.01 & $1.41[1.04-1.92]$ & 0.03 \\
\hline being made to accept ideas/brainwashing & $1.39[1.03-1.88]$ & 0.03 & NA & NA \\
\hline witnessing murder of stranger or strangers & $1.38[1.02-1.86]$ & 0.04 & NA & NA \\
\hline serious injury & NA & NA & $1.38[1.09-1.74]$ & $<0.01$ \\
\hline
\end{tabular}

Abbreviations: $\mathrm{Cl}$, confidence interval; PTSD, post-traumatic stress disorder; OR, odds ratio (adjusted); NA, not applicable or was not statistically significant $(P>0.05)$.

Multivariate analysis for demographic variables in table, and all individual trauma exposure variables shown in Table 3. Only statistically significant demographic variables $(P<0.05)$ following univariate analysis included in multivariate analysis.

Only statistically significant $(P<0.05)$ adjusted odds ratios from multivariate analysis presented.

* No longer married includes divorced/separated, widowed, forcibly separated.

Symptoms of PTSD (HTQ PTSD Score $=\geq 2.0)$ and depression $(\mathrm{HSCL}$ score $=\geq 1.75)$ 
Table 6: Multivariate analysis of demographic variables and cumulative trauma variables associated with PTSD and depression

\begin{tabular}{|c|c|c|c|c|}
\hline \multirow[t]{2}{*}{ Variable } & \multicolumn{2}{|c|}{ PTSD (N = 657) } & \multicolumn{2}{|c|}{ Depression $(\mathbf{N}=8 \mid 5)$} \\
\hline & OR $[95 \% \mathrm{Cl}]$ & $P$ value & OR $[95 \% \mathrm{Cl}]$ & $P$ value \\
\hline \multicolumn{5}{|l|}{ Demographic Variables } \\
\hline female & $2.20[1.67-2.90]$ & $<0.01$ & $4.12[2.91-5.84]$ & $<0.01$ \\
\hline no longer married* & $1.80[1.26-2.59]$ & $<0.01$ & $2.62[1.46-4.69]$ & $<0.01$ \\
\hline displaced $>5$ miles from home & NA & NA & $1.46[1.18-1.82]$ & $<0.01$ \\
\hline \multicolumn{5}{|l|}{ Cumulative trauma events } \\
\hline $0-3$ trauma events & ref & & ref & \\
\hline 4-7 trauma events & $2.43[1.3-4.4]$ & $<0.01$ & $2.31[1.4-3.8]$ & $<0.01$ \\
\hline $8-11$ trauma events & $4.62[2.7-7.8]$ & $<0.01$ & $5.07[3.1-8.4]$ & $<0.01$ \\
\hline $12-16$ trauma events & $6.51[3.7-11.3]$ & $<0.01$ & $5.84[3.5-9.7]$ & $<0.01$ \\
\hline
\end{tabular}

Abbreviations: $\mathrm{Cl}$, confidence interval; PTSD, post-traumatic stress disorder; OR, odds ratio (adjusted); NA, not applicable as not statistically significant $(P>0.05)$.

* No longer married includes divorced/separated, widowed, forcibly separated.

Multivariate analysis for demographic variables in table, and cumulative trauma event categories. Only statistically significant demographic variables

$(P<0.05)$ following univariate analysis included in multivariate analysis.

Only statistically significant $(P<0.05)$ adjusted odds ratios from multivariate analysis presented.

Symptoms of PTSD (HTQ PTSD Score $=\geq 2.0)$ and depression $(\mathrm{HSCL}$ score $=\geq 1.75)$

\section{Discussion}

This study provides evidence of extremely high exposure to traumatic events suffered by civilians in Gulu and Amuru districts of northern Uganda and indicates widespread human rights abuses in northern Uganda, corroborating other findings on trauma exposure in northern Uganda [26]. 43\% of respondents reporting having been abducted or kidnapped. Three quarters of respondents witnessed or experienced the murder of a family or friend, and over half of respondents reported having been beaten or tortured. Almost one in seven respondents had experienced rape and sexual abuse. These rates of rape and sexual abuse are substantially higher than reported in other studies of displaced persons using similar methodologies [24,27-29]. Evidence on sexual abuse of men is rare in conflict-affected populations, but in this study $8 \%$ of male respondents reported having been raped or sexually abused. Deprivation of essential goods and services by IDPs is demonstrated by the fact that $90 \%$ of respondents had experienced lack of food or water, almost two thirds had experienced ill health without access to medical care, and over three quarters had lacked housing or shelter. Over half of respondents had experienced 8 or more of the 16 trauma events covered in the questionnaire. The IDP camps were established by the Ugandan government to protect the civilians population but over half of the traumatic events listed in Table 3 had occurred while the respondents were living in a camp.

This study reveals extremely high levels of psychiatric morbidity amongst the IDP population in Gulu and Amuru districts. $54 \%$ of respondents met symptom criteria for PTSD and $67 \%$ of respondents met symptom criteria for depression. These results compare with rates for symptoms of PTSD and depression in Gulu district of $71 \%$ and $31 \%$ recorded in a previous study [26]. The study results of depression compare with rates of $26 \%$ in Adjumani district which has also been affected by the war in northern Uganda but less so than Gulu and Amuru districts, and rates of $17 \%$ in Bugiri district in the East of Uganda which has not been affected by the war in the North [30].

The levels of PTSD and depression recorded in this study are amongst the highest recorded globally using similar methodologies amongst displaced and conflict-affected populations. Rates of PTSD and depression amongst Guatemalan refugees in Mexico were recorded at $11.8 \%$ and $38 \%$ respectively [24]. Amongst Karenni refugees living in the Thai-Burma border, $4.6 \%$ and $41.8 \%$ of respondents met criteria for PTSD and depression [27]. A survey of Bosnian refugees in Croatia diagnosed PTSD and depression in $5.6 \%$ and $18.6 \%$ of respondents. In Afghanistan, rates of PTSD have varied between $20.4 \%$ to $42 \%$ and rates for depression from $38.5 \%$ to $68 \%$ [29,31].

The study found a number of significant associations of independent variables on outcomes of PTSD and depression. Women are at particularly high risk of poor mental health, along with people that are no longer married, as recorded in other studies on mental health of displaced populations [24,26-29,32]. Traumatic events with significant associations with PTSD and depression included rape or sexual abuse, unnatural death of family/friend, murder of stranger or strangers, and being tortured or beaten. The dose-response relationship between exposure to traumatic events and PTSD and depression is also consistent with other studies of displaced population 
$[24,27,28,33,34]$. This study also showed that the absence of basic social goods and services such as food, water and health care had a significant association with outcomes of PTSD and depression. The association between absence of food and poor mental health is reflected in some other studies of displaced populations [24,27]. This study also showed that while men reported higher exposure to traumatic events than women, men reported lower levels of mental distress. It has been previously suggested that women may be at higher risk of mental distress because of the psychological consequences of rape, the violent loss of partner and children, and of becoming a single parent or widow [35]. Pre-traumatic and post-traumatic factors have also been shown to influence levels of PTSD [36,37]. Further investigation on resilience amongst persons exposed to trauma and not exhibiting signs of PTSD is also required.

\section{Limitations}

This study has a number of limitations. Firstly, the crosssectional design means the findings cannot be generalised across northern Uganda, and only associations can be described between variables rather than attributing causation. Secondly, the study cannot highlight individual camps with particular needs because precision is too low due to the cluster survey design. Thirdly, the study was unable to consistently match the gender of interviewer and respondents. As a result, there may have been underreporting of certain sensitive traumatic events. Fourthly, IDPs not living in officially registered camps (for example, those hosted by relatives or friends or living in unregistered camps in Gulu Municipality) were not included in the study. These IDPs represent approximately $21 \%$ of the entire IDP population of Gulu and Amuru districts [4]. It is difficult to assess how the study health outcomes may vary between IDPs living in registered camps and those who are not. However, mortality outcomes between the two groups appear broadly similar [4]. Lastly, the validity of measuring mental health outcomes like PTSD in different cultural settings has been questioned $[38,39]$. However, the HTQ and HSCL-25 used in this study have been specifically developed for conflict-affected populations and have been widely used and validated in Asia, Africa, Latin America and Europe [16,19-24,26,27,40]. The instruments also had high internal reliability levels in this study using the Cronbach $\alpha$. However, an in-depth validation of the HTQ and HSCL instruments, including locallydeveloped cut off points, would make an important contribution to the understanding of mental health amongst IDPs in northern Uganda.

\section{Conclusion}

This study provides evidence to indicate vulnerability to trauma exposure and deprivation of essential goods and services suffered by IDPs in northern Uganda, and the resultant effects this has upon their mental health. Under international law, the primary responsibility for providing humanitarian protection and assistance to IDPs lies with the national authorities. However, the international community also has a right to offer support to IDPs but this right has not always been adequately fulfilled [41-43]. The Ugandan government and the international community need to strengthen comprehensive protection and social support for IDPs in the camps of northern Uganda to help reduce mental distress and as a preventative measure to reduce further exposure to trauma. Some direct interventions to reduce mental distress have shown some impact in northern Uganda, but further investigation on the effectiveness and feasibility of these interventions is required given the size of the population affected [44]. A meaningful resolution to the conflict in northern Uganda would facilitate a return by IDPs back to their homes, support a healing process, and help IDPs re-build their lives.

\section{Abbreviations}

CI: Confidence Interval; HTQ: Harvard Trauma Questionnaire; HSCL-25: Hopkins Symptoms Check List-25; IDP: Internally Displaced Person; OR: Odds Ratio; PTSD: Posttraumatic stress disorder.

\section{Competing interests}

The authors declare that they have no competing interests.

\section{Authors' contributions}

BR led the study concept and design, data collection, data analysis, and drafting of the manuscript. KFO participated in developing the study concept and design, data collection, review of data analysis, and review of the manuscript. JB participated in developing the study concept and design, review of data analysis, and review of the manuscript. TO participated in developing the study concept and design, data collection, and review of the manuscript. ES participated in developing the study concept and design, and reviewing the manuscript. All authors read and approved the final manuscript.

\section{Acknowledgements}

We thank Professor Ovuga for comments on the first draft of this paper. Assistance with data for the sample frame was provided by the World Food Programme (Gulu Office) and the International Organisation for Migration (Gulu Office). This work was supported by the Wellcome Trust [073109/ Z/03/Z].

\section{References}

I. International Crisis Group: Northern Uganda: Seizing the Opportunity for Peace Kampala/Nairobi/Brussels; 2007.

2. UNOCHA: Consolidated Appeal for Uganda 2006 (Revision): UN Office for the Coordination of Humanitarian Affairs. Kampala 2006.

3. Boas MHA: Northern Uganda IDP Profiling UNDP/GoU/FAFO: Kampala; 2005.

4. MoH/WHO/UNICEF/IRC: Health and mortality survey among internally displaced persons in Gulu, Kitgum and Pader districts, Northern Uganda 
2005 [http://www.who.int/hac/crises/uga/sitreps/Ugandamortsur vey.pdf]. Last access 6 May 2008

5. MSF-Holland: Internally Displaced Camps in Lira and Pader, Northern Uganda. A Baseline Health Survey. Preliminary Report 2004 [http:// www.msf.or.jp/news/baseline/Baseline.pdf]. Last access 6 May 2008

6. Human Rights Watch: Uprooted and Forgotten: Impunity and Human Rights Abuses in Northern Uganda Human Rights Watch: New York; 2005.

7. Allen T: Trial Justice: The International Criminal Court and the Lord's Resistance Army London: Zed Books; 2006.

8. Van Acker F: Uganda and the Lord's Resistance Army: The New Order No One Ordered Volume 103. Issue 412 African Affairs: The Journal of the Royal African Society; 2004:335-358.

9. UNOCHA: Consolidated Appeals Process UNOCHA: Kampala; 2005.

10. World Food Programme: IDP Camp Population Survey, Northern Uganda World Food Programme: Gulu; 2006.

II. Cohen J: Statistical power analysis for the behavioral sciences 2 nd edition. New Jersey: Lawrence Erlbaum; 1988.

12. Henderson RH, Sundaresan T: Cluster sampling to assess immunization coverage: a review of experience with a simplified sampling method. Bulletin of the World Health Organisation 1982, 60(2):253-60

13. SMART: Standardised Monitoring and Assessment of Relief and Transitions Programme (SMART). Smart Methodology, Version I. SMART 2005.

14. Milligan $P, N j i e ~ A$, Bennett $S$ : Comparison of two cluster sampling methods for health surveys in developing countries. International Journal of Epidemiology 2004, 33(3):469-76.

15. World Health Organization: Training for Mid-level Managers: The EPI Coverage Survey WHO Expanded Programme on Immunization: Geneva; 1991.

16. Mollica RF, et al:: The Harvard Trauma Questionnaire - Validating a Cross-Cultural Instrument for Measuring Torture, Trauma, and Posttraumatic-Stress-Disorder in Indo-Chinese Refugees. Journal of Nervous and Mental Disease 1992, 180(2): III-II6.

17. American Psychiatric Association: Diagnostic and Statistical Manual for Mental Disorders Fourth edition. American Psychiatric Association Washington, DC; 1994.

18. Mollica RM, Massagli L, M Silove D: Measuring Trauma, Measuring Torture Harvard University: Cambridge, MA; 2004.

19. Mollica RF, et al.: Indochinese versions of the Hopkins Symptom Checklist-25: a screening instrument for the psychiatric care of refugees. American Journal of Psychiatry 1987, I 44(4):497-500.

20. Hinton WL, et al: Screening for major depression in Vietnamese refugees: a validation and comparison of two instruments in a health screening population. Journal of General Internal Medicine 1994, 9(4):202-6.

21. Fawzi MC, et al.: The validity of posttraumatic stress disorder among Vietnamese refugees. Journal of Traumatic Stress 1997 IO(I): I0I-8.

22. Kleijn WC, Hovens JE, Rodenburg JJ: Posttraumatic stress symptoms in refugees assessments with the Harvard Trauma Questionnaire and the Hopkins symptom Checklist-25 in different languages. Psychological Reports 200I, 88(2):527-32.

23. Rasekh Z, et al.: Women's health and human rights in Afghanistan. JAMA 1998, 280(5):449-55.

24. Sabin M, et al:: Factors associated with poor mental health among Guatemalan refugees living in Mexico 20 years after civil conflict. JAMA 2003, 290(5):635-42.

25. Nunnally J: Psychometric Theory 2nd edition. New York: McGraw-Hill; 1978.

26. Vinck $P$, et al:: Exposure to war crimes and implications for peace building in northern Uganda. JAMA 2007, 298(5):543-54.

27. Lopes Cardozo B, et al:: Karenni refugees living in Thai-Burmese border camps: traumatic experiences, mental health outcomes, and social functioning. Soc Sci Med 2004, 58( I 2):2637-44.

28. Lopes Cardozo B, et al.: Mental health, social functioning, and attitudes of Kosovar Albanians following the war in Kosovo. JAMA 2000, 284(5):569-77.

29. Scholte WF, et al.: Mental health symptoms following war and repression in eastern Afghanistan. JAMA 2004, 292(5):585-93.

30. Ovuga $E$, Boardman J, Wasserman $D$ : The prevalence of depression in two districts of Uganda. Social Psychiatry and Psychiatric Epidemiology 2005, 40(6):439-45.
31. Lopes Cardozo B, et al.: Mental health, social functioning, and disability in postwar Afghanistan. JAMA 2004, 292(5):575-84.

32. Porter M, Haslam N: Pre-displacement and post-displacement factors associated with mental health of refugees and internally displaced persons: a meta-analysis. JAMA 2005, 294(5):602-12.

33. Neuner F, et al.: Psychological trauma and evidence for enhanced vulnerability for posttraumatic stress disorder through previous trauma among West Nile refugees. $B M C$ Psychiatry 2004, 4:34.

34. Mollica RF, et al.: Dose-effect relationships of trauma to symptoms of depression and post-traumatic stress disorder among Cambodian survivors of mass violence. $\mathrm{Br} J$ Psychiatry 1998, 173:482-8.

35. Johnson $\mathrm{H}$, Thompson $\mathrm{A}$ : The development and maintenance of post-traumatic stress disorder (PTSD) in civilian adult survivors of war trauma and torture: A review. Clinical Psychology Review 2008, 28(I):36-47.

36. Brewin CR, Andrews $B$, Valentine JD: Meta-analysis of risk factors for posttraumatic stress disorder in trauma-exposed adults. J Consult Clin Psychol 2000, 68(5):748-66.

37. Ozer EJ, et al:: Predictors of posttraumatic stress disorder and symptoms in adults: a meta-analysis. Psychol Bull 2003, 129(1):52-73.

38. Bracken PJ, Giller JE, Summerfield D: Psychological responses to war and atrocity: The limitations of current concepts. Soc Sci Med 1995, 40(8): 1073-1082.

39. Summerfield D: A critique of seven assumptions behind psychological trauma programmes in war-affected areas. Soc Sci Med 1999, 48(10): I449-62.

40. Mollica RF, Caridad KR, Massagli MP: Longitudinal study of posttraumatic stress disorder, depression, and changes in traumatic memories over time in Bosnian refugees. J Nerv Ment Dis 2007, 195(7):572-9.

41. Deng F: Report on the Representative to the Secretary-General on Internally Displaced Persons 2002. UN Doc.E/CN.4/2002/95

42. United Nations: In larger freedom: towards development, security and human rights for all. Report of the SecretaryGeneral. 2005. A/59/2005

43. Egeland J: Towards a stronger humanitarian response system. Forced Migration Review 2005:4-5. Special supplement

44. Bolton P, et al.: Interventions for depression symptoms among adolescent survivors of war and displacement in northern Uganda: a randomized controlled trial. JAMA 2007, 298(5):519-27.

\section{Pre-publication history}

The pre-publication history for this paper can be accessed here:

\section{http://www.biomedcentral.com/1471-244X/8/38/pre} pub

Publish with Biomed Central and every scientist can read your work free of charge

"BioMed Central will be the most significant development for disseminating the results of biomedical research in our lifetime. "

Sir Paul Nurse, Cancer Research UK

Your research papers will be:

- available free of charge to the entire biomedical community

- peer reviewed and published immediately upon acceptance

- cited in PubMed and archived on PubMed Central

- yours - you keep the copyright

Submit your manuscript here:

http://www.biomedcentral.com/info/publishing_adv.asp
BioMedcentral 